\title{
Influence on sensitivity to insecticides: a case study of a settled area and a game park in Liwonde
}

\section{Dylo Foster Pemba ${ }^{1}$, Jimmy Namangale ${ }^{2}$}

1. Biology Department Chancellor College, University of Malawi

2. Mathematics Department Chancellor College, University of Malawi Corresponding author: Dylo Pemba, Email: pembadyl@chanco.unima. mw

\section{Abstract}

The close proximity of Liwonde National Park to Liwonde town creates a unique situation of a large human population adjacent to a natural undisturbed animal reserve. The closeness of the two ecosystems has an impact on biology of mosquitoes of the area, such as susceptibility to insecticides. Susceptibility to insecticide was determined using knockdown bioassays. The mosquito, Anopheles gambiae, was exposed to $0.05 \%$ deltamethrin and $0.75 \%$ permethrin giving LT 50 and LT 90. The LT50 values for $A$. gambiae from the town was 17.23 minutes and those from the park, 14.7 minutes $(p<0.05)$. The calculated LT 90 values were 32.8 and 28.3 minutes respectively. These results suggest that human settlements using insecticides in mosquito control reduce susceptibility of mosquitoes to regularly used insecticides such as deltamethrin and permethrin in this study.

\section{Introduction}

Local but globally pervasive processes such as urbanization, land and water resource development, and habitat fragmentation, such as establishment of towns affect many diseases. Urbanization increases population density and facilitates disease epidemics and transmission ${ }^{1}$. Water resource development and deforestation affect vector breeding and human contact with water and forests, increase incidences of vector-borne diseases such as malaria. Habitat or environmental fragmentation brings people and wild mammals and birds into overlapping areas and fosters both zoonoses and the emergence of new diseases in people ${ }^{2}$. The process of change is associated with transient periods of complex high disturbance levels between two states of the ecosystem. These periods, or chronotones, are times of great communicable (and other) disease hazards and of opportunities for disease control ${ }^{1}$.

Malaria and dengue fever are two of the common mosquito vectored diseases spreading as a result of unplanned urbanization $^{3}$. The two primary mosquitoes causing these diseases have adapted from their nearby natural forest environments, where they breed in tree holes containing rainwater and temporary small pools, to the urban environment where they breed in drains, water cans, discarded tires, pots and bottles.

\section{Resistance in control of mosquitoes}

There are several mosquito control methods that have been developed and used over the years. One such method is by using chemicals in various ways and formulations. These include burning coils, aerosol spray, and insecticide residual spray (also known as Indoor Residual Spray (IRS).

Pyrethroids are the preferred insecticide group for treating bed nets because of their low mammalian toxicity, a quick knock down rate and repellence effect ${ }^{4}$. Insecticides used for spraying the walls of houses include DDT, pyrethroids, carbamates and organophosphates. The future of malaria vector control programmes depends on the vectors remaining susceptible to these insecticides ${ }^{5}$.

This use of chemicals to control mosquitoes faces the following challenges:

i) Most chemicals are poisonous to people.

ii) They are expensive and require special equipment and expertise to use.

iii) Resistance develops in the vector.

\section{Insecticide resistance mechanisms}

Insecticide resistance is defined by the WHO as the "development of an ability in a strain of an organism to tolerate doses of a toxicant which would prove lethal to the majority of individuals in a normal (susceptible) population of the species." 6,7.

Resistance to insecticides has always occurred where there is a history of intensive use of pesticides in vector control or agricultural fields such as cotton and rice fields ${ }^{7}$. Identification of mechanisms in insecticide resistance is one step after monitoring for successful alternative insecticides.

There are currently two main mechanisms for resistance particularly to pyrethroids in $A$. gambiae:

a) Reduced target zone sensitivity arising from a single point mutation in the sodium channel gene ${ }^{10}$.

b) Increased level of detoxifying enzymes ${ }^{8}$.

There are three main mechanisms of resistance to various insecticides in mosquitoes:

Target zone resistance (knock down resistance): The target zone for DDT and pyrethroids is the sodium channel in the insect's nervous system ${ }^{9}$. Pyrethroid resistance due to knock down (kdr) mutation is common in A. gambiae in West African and East Africa ${ }^{10}$.

Metabolic resistance: This resistance mechanism is based on an increased ability to hydrolyze model esterase substrate. Metabolic resistance to DDT and pyrethroids in malaria vectors is widely reported but poorly understood because the three families of enzymes involved (cytochrome P450, glutathione $\mathrm{S}$ transferase and estrases) have each many enzymes with overlapping properties ${ }^{11}$.

Behavioural resistance: Mosquitoes by their natural behaviour or modification avoid landing on insecticide treated surfaces or shorten the period of contact to such levels that insecticides do not get into their system ${ }^{12}$.

\section{The Study Area}

The increasing human population in Liwonde area and abrupt boundaries between the park and the town has resulted in the two very different ecosystems, namely human and animal settlements being in close contact only separated by an electric fence in some places or short stretches of mopane woodland.

In one ecosystem there is human population making extensive use of insecticides while in the other there are neither human hosts nor insecticides This close proximity of two ecosystems namely human habitation and undisturbed bush made Liwonde ideal area for study ${ }^{13}$. 


\section{Liwonde National Park}

Liwonde National Park (LNP) is part of Liwonde-Mangochi Protected Area Complex (LMPAC). The park is in the southern region of Malawi, stretching from the middle Shire River and the south east of Lake Malombe to Liwonde Township. A small section of the park extends west of the Shire River and into Lake Malombe. Its total area is $548 \mathrm{~km} 2$ . The park is located upon $14^{\circ} 50^{\prime} \mathrm{S}, 35^{\circ} 20^{\prime} \mathrm{E}^{14}$. The park has a large population of elephants, hippos, waterbuck, impala, sable and crocodiles ${ }^{15}$.

\section{Liwonde Town}

Liwonde Township is located along a road that connects Blantyre, Zomba, and Lilongwe in the southern part of Malawi. It is located in two districts -Machinga (mainly) and Balaka (in the west). It is assumed that the original landscape in terms of vegetation, soil, hydrology, climate, etc. before development took place was very similar to that of the present park. The boundary between the park and the town is very abrupt with most of the area under arable farming ${ }^{15}$. The Liwonde area has a population largely concentrated in the rapidly growing Liwonde Township estimated at 100,000 people $\mathrm{e}^{16,17}$

\section{Objectives}

To determine the influence of urbanization and town development on mosquito populations in the Liwonde Township and Liwonde National Park interface. This study was carried out to evaluate the possible build up of mosquito resistance to insecticides used in sprays and bed nets.

\section{Materials \& Methodology}

\section{Sampling Zones:}

The whole study areas was divided into zones A, B, C, D, E, F, G, H, J and I ( Figure 1). The demarcation was done based on vegetation type, presence and type of human habitation, presence of water bodies, type of water bodies, location in relation to either the park or town and presence of other physical features like roads. Larvae and adults were collected from 21 points within zones A, B, C, D, E, F, G, H, J and I.

Table 1 Description of sampling zones
\begin{tabular}{|l|l|}
\hline Zone & Physical characteristics \\
\hline A & $\begin{array}{l}\text { Low-density urban area of the town. Houses with large } \\
\text { lawns spaced by maize field. }\end{array}$ \\
\hline B & $\begin{array}{l}\text { Park area far from human settlement with typical park } \\
\text { vegetation- not sampled for mosquitoes. }\end{array}$ \\
\hline C & $\begin{array}{l}\text { Dense housing and population close to the river, with large } \\
\text { maize fields between houses when moving away } \\
\text { from the river. }\end{array}$ \\
\hline D & $\begin{array}{l}\text { Park area not far from human settlement with typical } \\
\text { park vegetation. The most accessed part of the park. }\end{array}$ \\
\hline E & $\begin{array}{l}\text { Customary land within villages out of park area, mostly } \\
\text { under arable cropping }\end{array}$ \\
\hline F & $\begin{array}{l}\text { Central commercial part of the town, with shops, offices etc } \\
- \text { few bushes or cultivation. }\end{array}$ \\
\hline G & $\begin{array}{l}\text { Buffer Zone between the park and high density township of } \\
\text { Liwonde town , few temporary homes, large areas with } \\
\text { poor drainage resulting in temporary swamps during rainy } \\
\text { season. Partly used for rice cultivation. }\end{array}$ \\
\hline
\end{tabular}

\begin{tabular}{|l|l|}
\hline $\mathrm{H}$ & $\begin{array}{l}\text { Customary land within villages, out of town area, mostly } \\
\text { under arable cropping }\end{array}$ \\
\hline $\mathrm{I}$ & $\begin{array}{l}\text { Dense housing and population close to the road, with large } \\
\text { maize fields between houses when moving away from the } \\
\text { road }\end{array}$ \\
\hline $\mathrm{J}$ & $\begin{array}{l}\text { Customary land within villages, out of town area, mostly } \\
\text { under arable cropping. }\end{array}$ \\
\hline
\end{tabular}

Figure 1: Satellite map showing sampling points in study area.

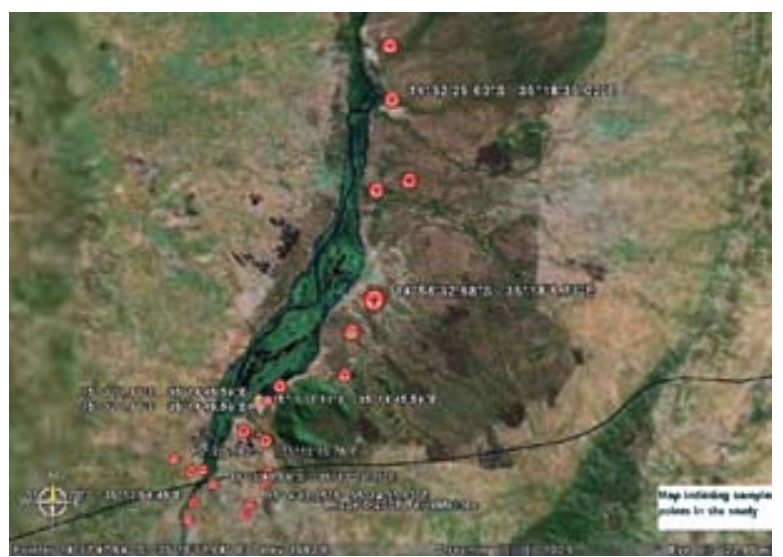

\section{Sampling}

Stratified random sampling was done every two months to show seasonal trends. However, frequency of sampling was modified due to accessibility and seasonal conditions. During the dry season sampling was not guided by random process but by the availability of water pools for larvae, which in most of the cases was along the rivers or in man-made water holes. Zone B was sampled once and the results were not included in the analysis. Sampling in B was ignored because it was very far away from the town and its influence or the influence of the town on mosquito population would be very minimal.

\section{Mosquito Sampling Techniques}

\section{Adults}

Two methods were used to collect mosquitoes:

1)Putter/Aspirator: A putter was used to capture live adults. These specimens were used to determine resistance levels. This method is also reliably used when determining feeding time of various species, distribution in the study area as well species complex. It also provides an indication of whether the species are anthropophagic or zoophilic.

2)Larva/pupal dipper: Mosquito larvae are found in a wide variety of habitats and therefore require different sampling techniques to ascertain their presence or absence and to estimate their numbers. Dipping was done around floating debris, aquatic and emergent vegetation logs and tree stumps in the water, and grasses around the margins with an improvised dipper.

Larval mosquito sampling was carried out using mosquito dipper for medium sized to larger, deeper pools or by singly picking larvae using wide mouth pipettes for tiny pools.

\section{Mosquito Rearing \\ Collecting and caging adults}

Anopheles mosquitoes were collected inside houses during the morning of each of the collection days using an aspirator/ putter. They were separated later into $A$. funestus group and A. gambiae complex. 
The mosquitoes were transferred into labelled containers covered with netting material. These containers were wrapped in a moist cloth and put in cooler boxes in order to keep the mosquitoes cool. The mosquitoes were transferred to cage, allowed to rest for about an hour before exposing them to insecticides. The idea was to select only vigorous mosquitoes for exposure.

\section{Larvae}

After collection, the larvae were put in water and the containers covered. A one third headspace volume of the container was left to provide air for the larval breathing while being transported to the laboratory. The larvae were kept in water troughs at $27^{\circ} \mathrm{C}$ in Gallenhamp incubator. They were given yeast 10 percent suspension solution or commercial aquarium fish food ${ }^{18}$. When they pupated they were picked and placed in emerging dish in cages.

\section{Mosquito Identification}

Mosquitoes were identified using morphological features usually used in classical non-biochemical identification methods. The features used include wing, scale pattern, tarsal arrangement, hair/scale pattern, antennae etc for the adults. For the larvae, larval hairs, respiratory siphon and screlotised plates were used, by following the Centers for Disease Control (CDC) larval identification key manual ${ }^{19}$.

The following aids were used for mosquito identification:

1. Computer aided identification using Afro-tropic mosquito and DimmLag mosquito identifying software.

2. Handbooks on mosquito identification: CDC manuals, and Anophelinae of Africa, South of Sahara ${ }^{20}$. Identification was done only to general level except in the case of Anopheles, where A. gambiae complex and A. funestus group were identified and separated from the rest for insecticide resistance analysis.

\section{Testing for Resistance to Deltamethrin \\ Testing Methods}

Lethal time (LT50) was used to determine larval resistance to deltamethrin. This is the period of time it takes to have fifty percent of the mosquitoes in the test kit knocked down by the insecticide ${ }^{21}$.

Bottle assay: The bioassays were carried out on two groups of mosquitoes, one group from Liwonde National Park, and the other from Liwonde town. Only Anopheles gambiae species were tested. This species was chosen because of its importance in malaria transmission and at the same time to avoid errors as a result of different mosquito species having a differential resistance threshold.

Deltamethrin $0.05 \%$ was used. Batches of 15 mosquitoes were transferred into each of the exposure bottles coated with insecticides. Tests had two replicates and a control treatment. The control treatment was coated with solvent only.

Test bottles were placed horizontally on the bench and the exposure period for all tests was one hour. Observations were made every ten minutes of the hour. Mosquitoes lying on their backs or sides were considered knocked down.

After 60 minutes, the mosquitoes (either alive or knocked down) were transferred to recovery cages provided with cotton pads socked in 10\% sucrose for 24 hours. Mortality was recorded after 24 hours from time of exposure.

\section{Determining Resistance Thresholds of Adults}

Interpretation of the susceptibility test was according to Zahar \& Davidson ${ }^{22}$ and WHO (1981) that $98 \%$ mortality equals susceptibility to the test insecticide. $80 \%$ to $98 \%$ mortality means verification is required and $80 \%$ mortality indicates resistant individuals are present in the study population. A population is considered resistant if more than $20 \%$ of population survives the diagnostic dose compared to the susceptible colony ${ }^{6}$.

\section{Larval Testing}

Deltamethrin in de-ionized water were prepared and put in $5 \mathrm{ml}$ vial. The insecticide was stored in dark glass bottles at 4 ${ }^{\circ} \mathrm{C}$. Five milliliter vials with $0.05 \%$ insecticide were prepared. Five late 3rd instar larvae were added to each vial. Third instar larvae were identified using body size since they are usually about two times the size of first instar larvae. A control with ethanol instead of the insecticide was used. Mortality was recorded at 5 minutes interval for one hour ${ }^{23}$.

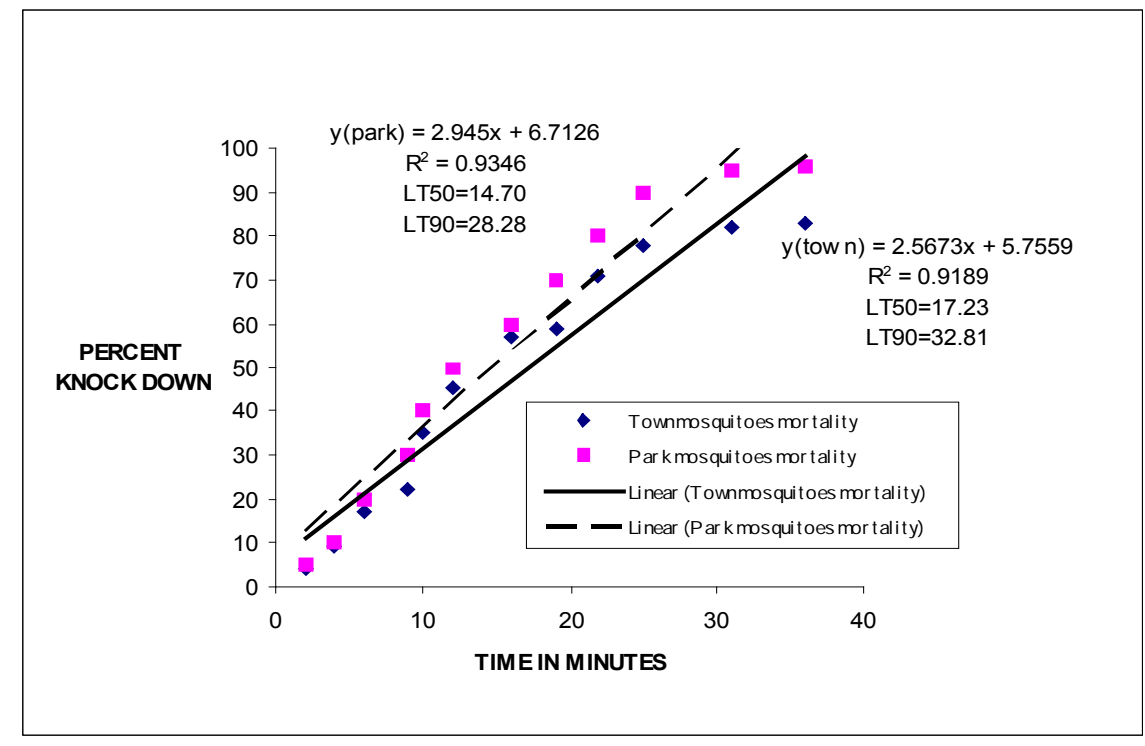




\section{Results and Discussion}

\section{Mosquito Resistance to Insecticides}

\section{Deltamethrin}

Figure 2, below shows the result of testing $A$. gambiae for resistance to $0.05 \%$ deltamethrin. The LT50 of Anopheles gambiae s.l mosquitoes from the park was 14.7 minutes and for the town the 17.2 minutes. The LT 90 value of Anopheles gambiae s.l from the Park was 28.3 .minutes and for those for the town 32.8 minutes.

These results show slightly reduced susceptibility of A.gambiae from Liwonde Town to deltamethrin as indicated by the reduced LT50 values for mosquitoes from the town though not statistically significant at LT90. (Mann-whitney U for $\mathrm{p}=\mathrm{LT} 50$, at 0.71 and LT 90 at 0.25 )

Permethrin results for $0.75 \%$ permethrin LT50 values of $A$. gambiae complex in relation to sampling location A.gambiae s.l from Park LT50 was 21 minutes and A.gambiae s.l from town LT50 was 24 minutes. When results of mosquitoes from town are compared to those of mosquitoes from the national park they show slightly reduced susceptibility of A.gambiae from Liwonde town to deltamethrin as indicated by the reduced LT50 values though not statistically significant. The higher LT50 values as compared to averages of national surveys suggest the following

- The existence of one or more mechanisms of pyrethroids resistance, which give cross-resistance between different pyrethroids. Resis $\neg$ tance to pyrethroids in Anophelines has been reported due to the involvement of monoxygenases and or esterases and a kdr-type (Pyrethroid knock down resistance) caused by a mutation in the sodium channel gene ${ }^{16}$ which is also known to confer cross-resistance with DDT. The mechanisms of pyrethroid resistance in the Anopheles in this study are however not known. One indicates a case of building resistance, which requires constant monitoring.

- Location Impact: The impact on susceptibility also varies depending on where the mosquitoes are from. Those from the Park are slightly more susceptible to insecticides as compared to those from the Town as indicated in results above. The likely reason for this susceptibility difference is that most of the homes in town, $61 \%{ }^{24}$ use pyrethroids based insecticides for mosquito control. Mosquitoes from the Town have been under increased chemical selection pressure than those from the Park, thus those remaining are the ones with increased resistance levels. This may also explain why there seem to be a slight increase in LT50 and LT90 values in Permethrin than Deltamethrin. Permethrin has been used in mosquito control in Malawi longer than Deltamethrin through aerosol sprays which could have resulted in longer periods of selection for resistance.

The results from this study indicate possible build-up of resistance to pyrethroid in Liwonde's settled area than unsettled areas though not statistically significant however it shows the need to keep monitoring to avoid letting the resistance reach higher levels that can reduce efficacy on ITNs.

\section{References}

1. Bradley DJ, An exploration of Chronotones: a concept for understanding the health processes of changing ecosystems. Ecohealth 2004: 1(2): 165-171.
2. Pimentel D, Tort M, D'Anna L, Krawic A., Berger J, Jessica R, Mugo F, Doon N, Shriberg M. Howard E, Lee S, \& Talbot J, Ecology of increasing disease: population growth and environmental degradation. Bioscience 1998:48 (10):165.

3. Chase JM \& Knight TM. Drought-induced mosquito outbreaks in wetlands. Ecology Letters 2003: 6(11):1017.

4. Coetzee M., Horne DWK., Brooke BD \& Hunt R.H. DDT, Dieldrin and Pyrethroid insectcide resistance in African Malaria vector mosquitoes: An historical review and implications for future malaria control in Southern Africa. South Africa Journal of Science (1999) 95: 215-218.

5. Hemingway J, Lindsay SW, Small GJ, Jawara M \& Collins FH. Insecticide susceptibility in individual species of the Anopheles gambiae complex (Diptera: Culicidae) in an area of the Gambia where pyrethroids impregnated bed nets are used extensively for malaria control. Bulletin of Entomological Research 1995: 85:229334.

6. WHO. Resistance of vectors and reservoirs of disease to pesticides. Tenth report of WHO expert committee on vector biology. Technical Report Series 818, Geneva World Health Organization .1986. \& WHO. Fifteenth report of vector resistance to pesticides expert committee on insecticide resistance. Technical Report Series 818, Geneva World Health Organization. 1992

7. WHO. Vector resistance to insectcicide : a review of its operational significance in malaria eradication and control programmes. WHO/ MAL/76.883. WHO/VBC/76.634. 1976

8. Brooke BD, Kloke G, Hunt RH., Koekemoer LL, Temu EA., Taylor ME, Small G, Hemmingway J \& Coetzee M. Bioassays and biochemical analyses of insecticide resistance in Southern African Anopheles funestus . Bulletin of Entomological Research 2001:91: 265-271.

9. Hemmingway J, \& Ranson H. Insecticide Resistance in insect vectors of Human disease. Annual Review of Entomology 2000:45: 371391.

10. Martinez-Torres D, Chandre F, Williamson MS, Darriet F, Berge JB, Devonshire AL, Gullet P, Pasteur N \& Pauron D. Molecular Characterisation of pyrethroid knockdown resistance $(\mathrm{kdr})$ in the major malaria vector An. gambiae s.s. Insect biochemistry and molecular biology 1998: 7:179-184

11. Collins FH, Kamau L, Ranson HA, \& Vulule JM. Molecular Entomology and Prospects for Malaria. Bulletin of the World Health Organization $2000: 78: 412-423$

12. WHO Manual on practical entomology in Malaria. Geneva. 1975

13. Newton G, Malaria: The mosquito resistance movement. Wellcome Trust online documents. http://www.welcometrust.org. 2002.

14. Government of Malawi. Protected areas master plan for the Southern Region; Volume IV . Department of National Parks and Wildlife, Lilongwe, Malawi. 1983

15. Bhima R., Liwonde National Park. African Journal of Ecology 1997: $34(1): 83-85$

16. National Statistical Office (NSO) Malawi Government 1998 Census. Zomba, Malawi. 1998

17. Thomson P, Master plan for Liwonde National Park. Department of National Parks and Wildlife. Lilongwe, Malawi. 1998

18. Ford HR \& Green E. Laboratory rearing of Anopheles albimanus Mosquito News 1972 :32: 509-513.

19. Center for Disease Control (CDC). Tropical Mosquito identification manual, 1998.

20. Gillies M, \& De Meillon B.. The Anophelinae of Africa south of The Sahara (Ethiopian Zoogeographical Region), 2nd Edition . The South African Institute for Medical Research No 54. 1968

21. WHO. Expert Committee on Insecticide Resistance. Technical Report Series 818, Geneva World Health Organization. 1991

22. Zahar AR. \& Davidson G.. The practical implication of resistance of malaria vectors to insecticides. Bulletin of World Health Organisation 1973: 29:475-483

23. WHO. Instructions for determining the susceptibility or resistance of adult mosquitoes to organochlorine, organophosphate and carbamate insecticides-Diagnostic Test. WHO/VBC/81.806,1-6. Geneva, Switzerland. 1981.

24. National Statistical Office (NSO). Malawi Demographic and Health Survey. Zomba, Malawi. 2000 